\title{
DETERMINING CRITERIA AND SUB-CRITERIA WEIGHTS FOR THE SELECTION OF REGIONAL CENTERS OF COMPETENCE IN CROATIA
}

\begin{abstract}
In this paper, a process of determining the criteria and sub-criteria weights for the selection of Regional Centers of Competence (RCC) in sector of vocational education is described. In 2018, the Croatian Ministry of Science and Education was responsible for creating a document comprising all parameters and criteria for this selection, named The Network of Regional Centers of Competence, and requested assistance in determining the criteria and sub-criteria weights to be incorporated within. The criteria were predefined pursuant to the national Vocational Education and Training Act and, to determine the weights, the AHP decision making group of the members of the Council for Vocational Education were engaged. There were 10 criteria with the total of 64 sub-criteria in this process, and to make it more efficient, pairwise comparison was made for the criteria and an inverse ranking method for the sub-criteria weights. Because of the enhanced number of pairwise comparisons, it was quite challenging for some decision makers to stay consistent. Therefore, the inconsistency coefficient was used to calculate the decision makers' weights, to incorporate the reliability of their comparisons in the overall process.
\end{abstract}

Keywords: analytic hierarchy process, group decision making, government, education

\section{Introduction}

In accordance with the Strategy of Education, Science and Technology adopted by the Croatian Parliament (2014), the Government of The Republic of Croatia adopted in year 2016 The Program for the Development of the Vocational Education and Training System. As the most prominent innovation and crucial for reform of the system of vocational education, the Program specifies the establishment of Regional Centers of Competence (RCC). Those Centers are planned to be the places of excellence in vocational education and training, where programs of regular vocational education, vocational training and lifelong learning, as well as other forms of formal and non-formal education (work-based learning, competitions and presentations of knowledge and skills, etc.), will be implemented. In order to support that huge step forward for vocational education and training system funding was planned within EU funds amounted almost 500 million Euro and it has been the biggest investment in Croatian vocational education in last 30 years. The minister made a decision to introduce 25 centers across all Croatian counties in five priority areas (electrotechnics and mechanics, computer science, agriculture, tourism and health care). In 2018, The Ministry of Science and Education was responsible for creating a document named The Network of Regional Centres of Competence including all the parameters and criteria for the selection of those Centres. For this selection process to be carried out transparently and with expertise, criteria and sub-criteria weights had to be determined. There were a few crucial elements that had to be considered here. First, the context with criteria and sub-criteria was predefined within the national Vocational Education and Training Act (amended in 2017 to include RCC). Second, the role of the national Council for Vocational Education is stated in the Act and includes its task "to give a preliminary opinion to the minister on the adoption of the Network and designation of International Symposium on the 
ISAHP Article: A Style Guide for Paper Proposals To Be Submitted to the International Symposium on the Analytic Hierarchy Process 2020, Web Conference.

RCC". Therefore, the Council members were included in a group decision making process. Third, there were 12 criteria at the beginning, which were slightly regrouped to obtain 10 of them before starting pairwise comparison. With such a large setting (64 sub-criteria) and Council members as important players in decision making process, the challenge was to propose the appropriate methodology to ensure efficient and effective process.

\section{Literature Review}

As a method for calculating criteria weights, the AHP was chosen, and an inverse ranking method for the sub-criteria weights. Having pairwise comparison of 10 criteria, there is a significant possibility of inconsistency, especially if persons performing the comparison lack experience in this kind of activity. In the performed survey of inconsistency indices for pairwise comparisons Brunelli (2018) states that the relation between inconsistency and group decision-making has become important since the most of the real-world decisions are made by groups and committees. It has been proven that the only aggregation method to obtain a group pairwise comparison matrix, which satisfies a number of reasonable properties, is the entry-wise weighted geometric mean of pairwise comparison matrices of individual decision makers (Aczél \& Saaty, 1983). One way of dealing with the appeared inconsistency and decision makers' weights is found in Cho, Y. G., \& Cho, K. T. (2008) with the use of a loss function. Toloie-Eshlaghy \& Nazari Farokhi (2011) model decision makers' weights considering the number of iterations in decision making matrix of each individual. In this paper, the proposed method for calculating decision makers' weights using consistency indices $(C I)$ is simply using the inverse values of consistency indices, normalized by the sum of all values.

\section{Objectives}

The overall objective of this paper is to show how high stake complex decision making at the national level can be supported by the AHP modelling in order to assure decisions that are accepted by all stakeholders and for which the transparency and broad inclusiveness were crucial. More specific objective is to demonstrate how to back up such procedures by facilitating group decision making process to be effective and taking into consideration the inconsistency along the way.

\section{Research Design/Methodology}

Criteria and sub-criteria was predefined within the national Vocational Education and Training Act. The criteria were as follows: Programs and relations with the labour market, Teachers of general education and vocational subjects, Interest of pupils for programs, Spatial and material conditions, Accommodation capacity, Cooperation with companies and higher education institutions, School project activities, Organizational capacities and knowledge transfer, Change management, developmental activities and quality assurance, Educational stages transitivity, Gravitational index and Development index of the county. Criteria weights were determined by the AHP. To determine sub-criteria weights an inverse ranking method was used, since the majority of criteria had between 7 and 12 sub-criteria, which would result in a lot of new pairwise comparisons. A workshop was held where Council for Vocational Education members were divided into groups according to their expertise and background so they could discuss the importance of criteria and sub-criteria from their point of view: headmasters, municipality representatives, union representatives, 
etc. Individual pairwise comparison matrices were aggregated as the entry-wise weighted geometric mean:

$$
A^{*}=\left(a_{i j}^{*}\right)_{n \times n}=\left(\prod_{k=1}^{m}\left(a_{i j}^{(k)}\right)^{\omega_{k}}\right)_{n \times n},
$$

where $A^{*}$ is aggregated matrix, $m$ is the number of decision makers, $a_{i j}^{(k)}$ are elements of $k$-th individual preference matrix and $\omega_{1}, \cdots, \omega_{m}$ decision makers' weights. Those weights were calculated using consistency indices $C I$, where those individuals who had higher consistency index, obtain smaller weight:

$$
\omega_{j}=\frac{\frac{1}{C I_{j}}}{\sum_{i=1}^{m} \frac{1}{C I_{i}}}, \quad j=1, \ldots, m .
$$

\section{Data/Model Analysis}

Listing the complete hierarchy here is not important, because it was predefined and not in the scope of this paper. There were 12 criteria at the beginning, which is quite a lot for a pairwise comparison. So, two similar numerical criteria with no sub-criteria were combined together (Gravitational and Development indices), as well as two criteria about premises (Spatial and material conditions, with Accommodation capacity). This resulted in 10 criteria for pairwise comparison with the combined criteria compared at the second level of hierarchy. Altogether, it significantly decreased the number of comparisons. Weights of the sub-criteria were obtained by inverse rankings, because in such a large setting this was appropriate and good enough. There were 14 decision makers in this process and the reason for grouping them by profession was to encourage them to discuss the importance of criteria and raise the level of consistency at the end. Unfortunately, 8 of them had consistency ratio more than $10 \%$, so the reliability of comparisons had to be manifested in assigning decision makers' weights. The 'smaller the better' approach was achieved by inverting the consistency indices and normalizing them by the sum. This proposed method has proven to be effective, since the final criteria weights were accepted.

\section{Limitations}

When dealing with such a large context, the obvious limitation is the reliability of the judgments, i.e. the inconsistency. This could be improved by structuring the hierarchy more carefully. Modeling the decision makers' weights using the consistency indices is closely connected to this issue. It would be interesting for a future research to do a sensitivity analysis regarding the method used for calculating decision makers' weights. Some of those methods were also mentioned here.

\section{Conclusions}

The main benefit of this weight modelling approach lies in raising the level of transparency and awareness of the selection processes' criteria in governmental context. By combining the pairwise comparison with the inverse ranking method and incorporating inconsistency in a proposed way, made the overall process quite efficient with acceptable results. At the end, the Council for Vocational Education agreed with the obtained criteria and sub-criteria weights which were then included in the Network and proposed to the minister for adoption. Based on that according to public call $25 \mathrm{RCC}$ were selected and until today all of them have been given access to EU funding for development. So, it can be concluded that facilitating the whole decision-making process was done successfully.

International Symposium on the Analytic Hierarchy Process 
ISAHP Article: A Style Guide for Paper Proposals To Be Submitted to the International Symposium on the Analytic Hierarchy Process 2020, Web Conference.

\section{Key References}

Aczél, J., \& Saaty, T.L. (1983). Procedures for Synthesizing Ratio Judgements, Journal of Mathematical Psychology 27 (1): 93-102

Brunelli, M. (2018). A survey of inconsistency indices for pairwise comparisons, International Journal of General Systems, 47:8, 751-771.

Cho, Y. G., \& Cho, K. T. (2008). A loss function approach to group preference aggregation in the AHP. Computers \& Operations Research, 35(3), 884-892.

Toloie-Eshlaghy, A., \& Nazari Farokhi, E. (2011). Measuring the importance and the weight of decision makers in the criteria weighting activities of group decision making process. American Journal of Scientific Research, 24, 6-12. 